\title{
QUALIDADE MICROBIOLÓGICA DE CARNE SUÍNA IN NATURA EM FEIRAS LIVRES NO VALE DO PARAÍBA, ALAGOAS, BRASIL
}

\author{
ALVES, Elizabeth Simões do Amaral ${ }^{1}$ \\ SANTOS, Claudilene Maria dos ${ }^{2}$ \\ SILVA, João Manoel da ${ }^{3}$ \\ SILVA, Paula Cibelly Vilela $\mathrm{da}^{4}$ \\ SANTOS, Tania Marta Carvalho dos ${ }^{5}$ \\ MEDEIROS, Elizabeth Sampaio de \\ BARBOSA, Julicelly Gomes ${ }^{7}$
}

\author{
Recebido em: 2020.04.24 Aprovado em: 2020.11.02ＩSSUE DOI: $10.3738 / 21751463.3784$
}

RESUMO: Nas últimas décadas, a suinocultura brasileira passou por processos de modernização em vários segmentos da produção, atingindo índices técnicos e econômicos semelhantes e, algumas vezes, melhores aos obtidos em países mais tradicionais na criação, especialmente por meio das tecnificações de produção que têm surgido nos últimos anos. Apesar da região Nordeste ser detentora do segundo maior rebanho suíno do Brasil, ainda são encontradas explorações informais, sem controle efetivo da produção e com condições higiênico-sanitárias duvidosas, tornando um ponto negativo no momento da escolha da carne e seus derivados, o que incide sobre o baixo consumo na região. A partir disto, objetivou-se com esse estudo avaliar as condições higiênico-sanitárias de carne suína comercializada em feiras livres do vale do Paraíba. Foram coletadas 20 amostras obtidas em feiras livres de quatro municípios do vale do Paraíba, Alagoas. As amostras foram coletadas assepticamente em recipientes estéreis e acondicionados em caixa isotérmica, contendo gelo reciclável, e encaminhadas ao Laboratório para análises microbiológicas. Foram observadas contagens elevadas de micro-organismos aeróbios mesófilos, variando de $<1,8 \times 10^{5}$ a $>2,5 \times 10^{6} \mathrm{UFC} / \mathrm{g}$, e encontrados coliformes a $45^{\circ} \mathrm{C}$ acima dos valores permitidos pela legislação em $80 \%$ das amostras, verificou-se a presença de Staphylococcus coagulase positiva em 25\% das amostras. Assim, as condições higiênico-sanitárias da carne suína proveniente de feiras livres de municípios do Vale do Paraíba, Alagoas, Brasil, podem refletir a maneira como são submetidas à manipulação e comercialização. Além disso, a exposição prolongada desse alimento sem qualquer tipo de refrigeração, contribui para elevados níveis de contaminação microbiana, podendo provocar riscos de toxinfecções alimentares, deterioração e perda da qualidade da carne para o consumidor final.

Palavras-chave: Qualidade microbiológica. Segurança alimentar. Micro-organismos Indicadores. Staphylococcus spp.

\section{MICROBIOLOGICAL QUALITY OF IN NATURA SWINE MEAT SOLD IN FREE FAIRS IN VALE DO PARAÍBA, ALAGOAS, BRAZIL}

SUMMARY: In the last decades, Brazilian swine farming has undergone modernization processes in several production segments, reaching technical and economic indices similar and, sometimes, better to those obtained in more traditional countries in the creation, especially through the production techniques that have emerged in recent years. Despite the Northeast region having the second largest swine herd in Brazil, informal farms are still found, without effective control of production and with dubious hygienic-sanitary conditions, making it a negative point when choosing meat and meat products, which on low consumption in the region. From this, the objective of this study was to evaluate the hygienic sanitary conditions of swine meat sold in free fairs in the Vale do Paraíba,

\footnotetext{
${ }^{1}$ ORCID id http://orcid.org/0000-0001-5078-4104 Programa de Pós-Graduação em Produção Animal, Centro de Ciências Agrárias, Universidade Federal de Alagoas.

${ }^{2}$ Programa de Pós-Graduação em Produção Animal, Centro de Ciências Agrárias, Universidade Federal de Alagoas.

${ }^{3}$ ORCID iD http://orcid.org/0000-0002-7654-5475 Engenheiro Agrônomo, Mestre em Ciências. Experiência em Microbiologia Agrícola e Ambiental e Microbiologia de Alimentos.

${ }^{4}$ ORCID iD http://orcid.org/0000-0003-2157-4698 Programa de Pós-Graduação em Produção Animal, Centro de Ciências Agrárias, Universidade Federal de Alagoas

${ }^{5}$ ORCID iD http://orcid.org/0000-0002-1816-7840 Laboratório de Microbiologia Agrícola, Centro de Ciências Agrárias, Universidade Federal de Alagoas

${ }^{6}$ ORCID iD http://orcid.org/0000-0002-1289-2902 Departamento de Medicina Veterinária, Universidade Federal Rural de Pernambuco

${ }^{7}$ Universidade Federal De Alagoas, Campus Arapiraca - Unidade De Ensino Viçosa
}

Nucleus Animalium, v.12, n.2, nov. 2020 
Alagoas, Brazil. Twenty samples were collected from free fairs in four municipalities in the Vale do Paraíba. The samples were collected aseptically in sterile containers and placed in an isothermal box, containing recyclable ice, and sent to the Laboratory for microbiological analysis. High counts of aerobic mesophilic microorganisms were observed, ranging from $<1.8 \times 10^{5}$ to $>2.5 \times 10^{6} \mathrm{CFU} / \mathrm{g}$, and coliforms were found at $45^{\circ} \mathrm{C}$ above the values allowed by legislation in $80 \%$ of the samples, the presence of Staphylococcus was verified positive coagulase in $25 \%$ of the samples. Thus, the hygienic-sanitary conditions of pork from free markets in the municipalities of Vale do Paraíba, Alagoas, Brazil, may reflect the way in which they are subjected to handling and commercialization. In addition, the prolonged exposure of this food without any type of refrigeration, contributes to high levels of microbial contamination, which can cause risks of food poisoning, deterioration, and loss of meat quality for the final consumer.

Keywords: Microbiologycal quality. Food safety. indicators microorganisms. Staphylococcus spp.

\section{INTRODUÇÃO}

A suinocultura é uma das atividades da agropecuária mais difundidas e produzidas no mundo todo, sendo a carne suína uma das proteínas animais mais consumidas nos diversos continentes, representando grande importância econômica em diversos países (THOMS et al., 2010).

Segundo a Associação Brasileira da Indústria Produtora e Exportadora de Carne Suína (ABIPECS), a carne suína responde por cerca de 50\% do consumo global de carnes, sendo Hong Kong, Tailândia, União Europeia e China, o maior consumo per capita de carne suína mais elevados, sendo de $68,60,42,30,41,90$ e $37,50 \mathrm{~kg}$, respectivamente. No entanto, no Brasil chega apenas à 15,1kg por habitante/ano (ABIPECS, 2012).

Contudo, no Brasil, observa-se um cenário contrastante na produção de suínos, onde nas regiões Sul, Sudeste e Centro-Oeste, a suinocultura apresenta-se tecnificada e com altos índices de produtividade, enquanto nas regiões Norte e Nordeste, ainda se encontra como uma atividade rústica e de subsistência. Assim, a suinocultura brasileira não se restringe apenas a granjas com maior nível tecnológico, mas existem rebanhos com menor aporte de tecnologias, voltadas basicamente para o autoconsumo (SILVA FILHA, 2008).

Além dos baixos índices produtivos, a região Nordeste ainda responde por grande parte da produção informal, por apresentar baixo controle sanitário na produção e diversos problemas higiênico-sanitários durante a comercialização dos produtos. Segundo Martins et al. (2007), desde o abate dos animais até a sua comercialização em feiras livres, as carcaças passam por sérios riscos de contaminação, o que pode levar a redução da validade comercial, ou ainda, ser fonte de toxinfecções alimentares, colocando em risco a saúde coletiva.

Para Gomes et al. (2012), as feiras livres se destacam pela comercialização de alimentos in natura, grande variedade de produtos e pela diversidade de preços. Há uma preferência do consumidor por estes locais, devido à crença de que os alimentos ali comercializados são sempre 
frescos e de qualidade superior. Entretanto, vale ressaltar que nas feiras livres, os alimentos estão expostos à várias situações que propiciam a sua contaminação, das quais podem ser citadas a contaminação através do/a manipulador/a quando o/a mesmo/a não adota práticas adequadas de manipulação, a exposição do alimento para venda, bem como o seu acondicionamento e armazenamento em condições inapropriadas (ATAÍDE et al., 2019).

No Brasil, particularmente em feiras livres das pequenas cidades do interior do país, os perigos de contaminação microbiológica dos alimentos durante o abate e comercialização dos produtos são constantes, sendo frequentes a observação da prática da venda de carnes abatidas clandestinamente, em condições precárias de transporte, armazenamento e manipulação, com carcaças expostas ao ambiente, sem refrigeração e com duvidosas condições de higiene do estabelecimento, colocando em risco a saúde do manipulador e consumidor dos produtos cárneos (SOUZA, 2012).

A carne suína é uma fonte de proteína de alto valor biológico, possuindo todos os aminoácidos essenciais e em maior conteúdo em relação à carne bovina. Também possui alta digestibilidade, está entre as principais fontes de vitaminas do complexo $\mathrm{B}$, ferro de alta disponibilidade e possui menor teor de gordura e calorias do que muitas outras carnes (MIELE; MACHADO, 2010).

Por seu teor em nutrientes, por suas qualidades sensoriais e pela influência de certos fatores ambientais, como transporte e armazenamento, por exemplo, a carne suína é um alimento altamente perecível. No entanto, essa riqueza na composição química da carne torna-a um importante meio de cultura para a maioria dos micro-organismos, sendo excelente substrato onde penetram, crescem e multiplicam numerosas espécies e variedades de bactérias, leveduras e bolores, capazes de produzir alterações no aspecto, no sabor, no cheiro e em outras qualidades dos alimentos (ALMEIDA et al., 2010), além da possibilidade do alimento não estar seguro ao chegar no consumidor final.

A microbiota das carnes é proveniente de diversas fontes, como dos pelos do animal (devido ao contato com o solo, ração, fezes, água, dentre outros) e do sistema digestivo, o qual pode ser perfurado durante o corte das carcaças e acabar contaminando as peças. Além disso, as facas, os panos e os utensílios utilizados pelos operários durante o retalhamento, a evisceração e a desossa podem favorecer a contaminação (OLIVEIRA et al., 2008; LUNDGREN; SILVA; FERNANDES, 2009). - Assim como as condições de armazenamento e transporte.

Nos açougues/estabelecimentos comercializadores de carnes também pode haver contaminação pela manipulação direta das carnes, sem o uso de luvas pelos manipuladores, os quais, mesmo assintomáticos podem transmitir micro-organismos deteriorantes ou patogênicos, 
pondo em risco a saúde do consumidor, que pode ser acometido por Doenças Veiculadas por Alimentos - DVA's (OLIVEIRA et al., 2008; LUNDGREN; SILVA; FERNANDES, 2009).

Os micro-organismos indicadores das condições sanitárias são grupos ou espécies que, quando presentes em um alimento, podem fornecer informações sobre a ocorrência de contaminação de origem fecal, sobre a provável presença de patógenos ou sobre a deterioração potencial do alimento, além de poderem indicar condições sanitárias inadequadas durante o processamento, produção ou armazenamento (LANDGRAF, 2004).

A determinação desse grupo de micro-organismo é de fundamental importância, pois, dentro dele, alguns são potencialmente patogênicos para os humanos. Estas bactérias desenvolvem papel importante na saúde coletiva, uma vez que são responsáveis pelas infecções e toxinfecções alimentares causadas nos surtos de DVA’s (SILVA JUNIOR, 2007).

O controle de qualidade exercido pelos órgãos competentes como a vigilância sanitária sobre os referidos agentes biológicos tem por objetivos, impedir o seu ingresso na plataforma de processamento, a contaminação cruzada entre carcaças contaminadas e não contaminadas e eliminar a contaminação das carcaças adquirida no processo de abate (PORTO, 2006).

É importante frisar que a maioria desses problemas pode ser controlada. Sem dúvida a conscientização dos manipuladores, dos processadores, daqueles que de uma forma ou de outra trabalham com alimentos contribui para evitar ou diminuir os surtos de doenças veiculadas por alimentos (ANDRADE, 2008).

Diante do exposto, objetivou-se por meio desse estudo avaliar as condições higiênico sanitárias da carne suína comercializadas in natura nas feiras livres do Vale do Paraíba, Alagoas, Brasil, por meio das análises microbiológicas de contagens de micro-organismos.

\section{MATERIAL E MÉTODO}

\section{Amostragem}

A pesquisa foi desenvolvida em quatro cidades do vale do Paraíba: Atalaia, Capela, Cajueiro e Chã Preta. Foram coletadas amostras aleatoriamente de carne suína comercializadas em feiras livres. Da mesma forma como as carcaças estavam expostas para os consumidores nos locais de comercialização, sendo coletadas quatro amostras de cada cidade, sendo estas expostas por sobre as bancadas de comercialização, ausentes de refrigeração, e verificada também a existência de manuseio de dinheiro pelas mesmas pessoas que comercializavam o produto. De cada ponto foi realizada a coleta de $500 \mathrm{~g}$ de carne.

As amostras foram acondicionadas em sacos plásticos estéreis e identificadas com o nome da cidade e amostra 1, 2, 3, e 4. Em seguida foram transportadas em caixas isotérmicas, com gelo 
reciclável suficiente para cobertura total das amostras. No laboratório, após a limpeza externa da embalagem com álcool a 70\% para a remoção dos contaminantes presentes, as carnes foram amostradas no interior de fluxo laminar conforme recomendação de Silva, Junqueira e Silveira (2001).

Foram feitas análises para contagem de coliformes à $45^{\circ} \mathrm{C}(\mathrm{NMP} / \mathrm{g})$, contagem total de Bactérias Aeróbias Mesófilas (UFC/g) e pesquisa de Staphylococcus coagulase positiva (SPECK, 1976; SIQUEIRA, 1995; JAY, 2005).

\section{Procedimento}

Para o preparo das amostras foram pesados assepticamente em balança de precisão $25 \mathrm{~g}$ de cada amostra, em seguida adicionados à um recipiente hermético contendo $225 \mathrm{~mL}$ de solução salina estéril. Após esta etapa procedeu-se com a homogeneização por aproximadamente 60 segundos em Stomacher (SPLABOR), desta forma obteve-se a diluição $10^{-1}$, em seguida procedeu-se com as diluições seriadas $10^{-2}, 10^{-3}$ e $10^{-4}$ adotando os mesmos procedimentos. Estas diluições foram utilizadas para as análises de todos os micro-organismos. As análises microbiológicas foram realizadas de acordo com recomendações oficiais do Manual de Microbiologia de Alimentos de Origem Animal e Água do Ministério da Agricultura (MAPA, 2018).

\section{Contagem Total de Bactérias Aeróbias Mesófilas (UFC/g)}

Para a análise de mesófilos utilizou-se o ágar fundido, misturado à diluição com o ágar em temperatura de $45^{\circ} \mathrm{C}$ duplicadamente. A inoculação em placas de Petri foi realizada por meio de semeadura de $1 \mathrm{~mL}$ de cada diluição seriada em placas estéreis contendo (Ágar padrão para contagem). Seguidamente foram incubadas invertidas em estufa bacteriológica a $35{ }^{\circ} \mathrm{C}$ durante 48 horas. A leitura foi realizada contando-se nas placas previamente inoculadas e incubadas, o número de colônias que cresceram na placa, sendo expressos por Unidade Formadora de Colônia (UFC/mL) por placa.

\section{Contagem de coliformes à $45^{\circ} \mathrm{C}(\mathrm{NMP} / \mathrm{g})$}

Para a contagem de coliformes seguiu-se a técnica pelos tubos múltiplos do número mais provável (NMP/g), conforme protocolo recomendado por Silva, Junqueira e Silveira (2001; MAPA, 2018). De cada diluição seriada $\left(10^{-1}\right.$ a $\left.10^{-3}\right)$ do alimento em estudo foram tomadas três porções de $1 \mathrm{~mL}$ cada e inoculadas, respectivamente, em três tubos contendo $10 \mathrm{mlL}$ de Caldo Lauril Sulfato Triptose (LST MERCK 10266) contendo um tubo de Durhan invertido, obtendo-se 
três séries de três tubos, os quais foram incubados em estufa a $35-37{ }^{\circ} \mathrm{C}$, por 48 horas. Os subcultivos positivos com formação de gás no interior do tubo de Durhan foram semeados em tubos de Caldo Escherichia coli (EC MERK 10765), contendo tubos de Durham invertidos, e incubados a $45{ }^{\circ} \mathrm{C}$, em banho-maria, para a determinação de coliformes à $45{ }^{\circ} \mathrm{C}$. Após a incubação por 24 horas foi realizada a leitura, e os tubos que apresentavam turvação do meio e produção de gás no interior do tubo de Durham foram considerados positivos para bactérias do grupo coliforme à $45{ }^{\circ} \mathrm{C}$. Para cada diluição, o número de tubos positivos foi anotado e quantificado através da tabela de NPM (JAY, 2005), determinando, assim, o NPM de coliformes a $45^{\circ} \mathrm{C}$ por grama de carne analisado.

\section{Identifieação Contagem de Staphylococcus coagulase positiva}

Para o procedimento de contagem do Staphylococcus coagulase positiva, seguiu-se a metodologia descrita por Silva, Junqueira e Silveira (2001) e MAPA (2018). Foi realizada a semeadura na superfície de placas de Agar Baird-Parker (BP), com auxílio de alça de Drigalsky, a partir da inoculação de $0,1 \mathrm{~mL}$ das diluições selecionadas. A incubação foi realizada em estufa microbiológica a $35^{\circ} \mathrm{C}$ por 48 horas. Para a contagem foram selecionadas placas com 20 a 200 colônias, sendo contadas as colônias típicas e atípicas (com características morfológicas do micro-organismo em estudo - Stephylococcus e Streptococcus). Foram selecionadas as colônias típicas para o teste de catalase. Esse teste permite separar os Streptococcus catalase negativa de outros cocos Gram-positivos produtores de catalase, por exemplo, Staphylococcus. Assim, a enzima catalase converte o peróxido de hidrogênio contido no meio em oxigênio e água. A liberação do oxigênio se observa pela formação de bolhas.

Em seguida, transferiram-se algumas colônias típicas e atípicas para um tubo de caldo infusão de cérebro coração (BHI) incubado a $35{ }^{\circ} \mathrm{C}$ por 24 horas. A confirmação como Staphylococcus coagulase positiva, foi realizado por meio do teste de coagulase. Para isso, transferiu-se 0,2 mL de cada cultura obtida em BHI, para um tubo, adicionados aos 0,2 mL de cultura e 0,5 mL de coagulase plasma-EDTA e misturado com movimentos de rotação, sem agitar os tubos. Os tubos foram incubados em banho-maria a $37{ }^{\circ} \mathrm{C}$ e observado a cada uma hora, se houve formação de coágulo. As contagens de Staphylococcus foram obtidas pela multiplicação do número de colônias pela recíproca da diluição utilizada e os resultados expressos como $\mathrm{UFC} / \mathrm{g}$. 


\section{RESULTADOS E DISCUSSÃO}

Os resultados obtidos nas análises microbiológicas foram comparados com valores preconizados pela legislação brasileira, descrito na Resolução ${ }^{\circ} 12$ de 02 de janeiro de 2001, da Agência Nacional de Vigilância Sanitária (ANVISA, 2001). Na tabela 1 estão expressos os dados para os resultados das análises microbiológicas.

Tabela 1. Resultados da avaliação microbiológica de carne suína in natura comercializada em Feiras livres do Vale do Paraíba.

\begin{tabular}{ccc}
\hline Micro-organismos & Contagem & $\begin{array}{c}\text { Padrão Microbiológico } \\
\text { (MAPA, 2018) }\end{array}$ \\
\hline Coliformes a $45{ }^{\circ} \mathrm{C}(\mathrm{NMP} / \mathrm{g})$ & $7,5 \times 10^{2}$ a $2,1 \times 10^{2}$ & $5 \times 10^{2}$ \\
\cline { 2 - 2 } $\begin{array}{c}\text { Staphylococcus coagulase positiva } \\
(\text { UFC/g) }\end{array}$ & $1,5 \times 10^{2}$ & $5 \times 10^{2}$ \\
\hline Mesófilos (u/25g) & $1,8 \times 10^{3}$ & $1,2 \times 10^{5} \mathrm{a}>2,5 \times 10^{6}$ \\
\hline
\end{tabular}

Fonte: Elaborado pelos Autores

$\mathrm{Na}$ contagem de bactérias aeróbias mesófilas foram encontrados elevados valores, variando de $<1,2 \times 10^{5}$ a $>2,5 \times 10^{6} \mathrm{UFC} / \mathrm{g}$. Estes resultados se enquadram dentro dos valores na mesma pesquisa feita por Sales et al. (2013), que fazendo a avaliação da qualidade microbiológica da carne suína comercializada em condições similares às deste estudo, em Mossoró-RN, verificaram uma variação de $<3,0 \times 10^{5}$ a $>3,0 \times 10^{6}$ UFC/g na contagem padrão em placas de micro-organismos mesófilos.

A legislação brasileira não prevê limites para contagem em placas de bactérias aeróbias mesófilas em carne suína (BRASIL, 2018). Segundo Silva Junior (2007), para os alimentos que não contêm padrões estabelecidos para contagem microbiana total, destinados ao consumo humano, com populações microbianas da ordem de $10^{6} \mathrm{UFC} / \mathrm{g}$ ou $\mathrm{mL}$, como neste estudo, onde uma amostra obteve contaminação no valor de $2,5 \times 10^{6}$, devem ser considerados no mínimo suspeitos, pois aumenta a possibilidade de estarem presentes bactérias deterioradoras e/ou patógenas, podendo ocorrer descaracterização sensorial, perdas do valor nutricional e da atratividade do alimento. A presença elevada de mesófilos sugere a ausência de higienização no processamento do alimento.

Verificou-se que todas as amostras avaliadas apresentaram crescimento para a mesma e estes valores podem alterar as características sensoriais da carne suína (SILVA JUNIOR, 2007), pois, no que afirmam Lira e Pereira (2001), a ausência desse grupo de micro-organismos indica que a manipulação e as condições de conservação foram adequadas. 
Para Franco et al. (2008) e Franco e Landgraf (2005), a presença desse grupo de microorganismos significa que houve condições para o crescimento de patógenos, pondo em risco a saúde do consumidor. Dessa forma, a contagem das mesmas permite não somente indicar a qualidade higiênica do ambiente, mas também o tempo útil de conservação (MERCK, 1994).

Já na contagem de coliformes à $45^{\circ} \mathrm{C}$ pela técnica de Número Mais Provável (NMP), que é muito utilizada para avaliar condições higiênicas, sendo que altas contagens significam contaminação pós processamento, limpezas e sanificações deficientes, tratamentos térmicos ineficientes ou multiplicação durante o processamento ou estocagem.

Nesse estudo foi constatado um número elevado de coliformes totais $(7,5 \times 10$ a $>1,1$ x $10^{3} \mathrm{NMP} / \mathrm{g}$ ), estando apenas um percentual de $15 \%$ das amostras dentro do padrão estabelecido segunda a normativa RDC 12 (ANVISA, 2001), enquanto que 85\% estavam fora dos padrões preconizados pela legislação (MAPA, 2018).

A presença elevada de coliformes termotolerantes determina condições sanitárias insatisfatórias desse alimento e apresentação potencial de patógenos. A existência de coliformes termotolerantes é um desafio para a indústria alimentícia, pois é de preocupação nacional e internacional os perigos voltados à saúde do consumidor (FRANCO; LANDGRAF, 2002).

Martins et al. (2007), estudando o perfil microbiológico da carne suína in natura comercializada em feiras livres, em supermercado? na microrregião do Brejo Paraibano, detectaram a presença destes micro-organismos com valores variando entre $3,5 \times 10^{3}$ a $5,3 \times 10^{6}$ $\mathrm{NMP} / \mathrm{g}$, sendo que $33 \%$ e $95 \%$ das amostras mostraram-se com contaminação acima dos padrões recomendados para a manutenção da qualidade da carne, para coliformes totais e termotolerantes, respectivamente. Em comparação com os resultados do presente estudo, nota-se que foram inferiores aos de Martins et al. (2007), cujos valores encontrados correspondem ao percentual de $80 \%$ das amostras com contaminação acima dos padrões recomendados.

Outra análise importante foi (texto deve estar no passado) a contagem de Staphylococcus coagulase positiva, que indica manipulação inadequada e é uma bactéria patógena ao ser humano, onde as altas contagens obtidas estão relacionadas à uma precária condição de manipulação e ainda acena com a possibilidade destes produtos serem potencialmente capazes de causar DVA, uma vez que Staphylococcus aureus. acima de $10 \mathrm{x}^{5} \mathrm{UFC} / \mathrm{g}$ pode produzir enterotoxinas suficientes para causar doença no consumidor (ALBUQUERQUE et al., 2006).

A contagem de Staphylococcus coagulase positiva variou entre $1,8 \times 10^{2} \mathrm{UFC} / \mathrm{g}$ e $2,5 \mathrm{x}$ $10^{3} \mathrm{UFC} / \mathrm{g}$, e de todas as 20 amostras analisadas, 25\% apresentaram contaminação por Staphylococcus coagulase positiva, o que reflete na manipulação inadequada dos alimentos durante a comercialização das carnes suínas nas feiras destes municípios, como, por exemplo, o 
manuseio de dinheiro durante a comercialização, trânsito de animais como cães e gatos no ambiente, presença de insetos como moscas, além de que a comercialização da carne era realizada por sobre balcões expostos.

Esses resultados podem ser justificados pela resolução 275/02 do Ministério da Saúde (2002), em que todos os manipuladores da área de alimentos devem se manter adequadamente higienizados, o que não foi verificado. Todos os manipuladores falam e manuseiam dinheiro ao mesmo tempo em que manipulam alimentos e, não se faz uso de água corrente nem sabão antisséptico e é verificado transporte e acondicionamento da carne para comercialização (BRASIL, 2017).

Nenhum dos manipuladores utilizavam uniformes nem proteção para os cabelos, conforme verificado por Audi, (2002), que ao analisar 371 manipuladores verificou que mais da metade não obedecem a legislação, onde as mesmas observações foram feitas nas cidades nesse estudo.

Produtos cárneos são frequentemente associados a surtos de DVA segundo Welker et al. (2010), e uma carga microbiana muito elevada pode aumentar os riscos de intoxicações alimentares e perdas de qualidade dos produtos. Assim, fazem-se necessários estudos mais detalhados sobre as condições higiênico-sanitárias ao longo da comercialização em feiras livres para que seja possível a identificação dos pontos de contaminação dos produtos e que possam ser tomadas medidas eficazes que garantam a segurança alimentar da carne suína para a população consumidora dessas carnes.

Ademais, as possíveis contaminações de DTA's oriundas de produtos cárneos é uma consequência de má manipulação, especialmente no beneficiamento dos mesmos. Outro fator importante é a ausência ou deficiência de instruções adequadas para esses feirantes, onde os mesmos estão habituados a essas más práticas de manipulação.

\section{CONCLUSÃO}

As condições higiênico-sanitárias da carne suína comercializada de feiras livres de municípios do Vale do Paraíba, Alagoas, Brasil, podem refletir a maneira como são submetidas à manipulação e comercialização. Além disso, a exposição prolongada desse alimento sem qualquer tipo de refrigeração, contribui para elevados níveis de contaminação microbiana, podendo provocar riscos de toxinfecções alimentares, deterioração e perda da qualidade da carne para o consumidor final.

Ademais, é importante estabelecer nesses ambientes ações de conscientização para esse grupo de comerciantes, especialmente por meio de ações de órgãos públicos como a Agência 
Nacional de Vigilância Sanitário, por meio de parceiros locais, como as Universidades, por exemplo.

\section{REFERÊNCIAS}

ALBUQUERQUE, F. W.; BARRETO, N. S. E.; SILVA, A. I. M.; VIEIRA, R. H. S. Ocorrência de Vibrio parahaemolyticus e Estafilococos Coagulase positivo, em sushis comercializados em alguns estabelecimentos de Fortaleza- CE, Higiene Alimentar, v. 20, n. 146, p. 58-61, 2006.

ALMEIDA, A. C.; SOUZA, R. M.; PINHO, L.; MACEDO SOBRINHO, E.; SILVA, B. C. M. Determinação de perigos microbiológicos em carnes bovinas resfriadas provenientes de abates clandestinos e comércio ilegal. Acta Veterinaria Brasilica, v. 4, n. 4, p. 278-285, 2010. https://doi.org/10.21708/avb.2010.4.4.1580

ANDRADE, N. J. Higiene na Indústria de Alimentos. São Paulo: Varela, 2008.

Associação Brasileira Da Indústria Produtora E Exportadora De Carne Suína - ABIPECS.

Relatório Anual 2011-2012. Disponível em: 〈www.abipecs.com.br〉. Acesso em: 10 mar. 2020.

ATAÍDE, C. B.; SILVA, S. G. M.; SILVA, J. M.; ROCHA, J. R.; SANTOS, J. M. S.; SANTOS, T. M. C. Qualidade microbiológica de Caldo de cana-de-açúcar comercializado em feira livre de União dos Palmares, Alagoas. Revista Verde de Agroecologia e Desenvolvimento Sustentável, v. 14, n. 5, p. 650-653, 2019. doi: 10.18378/rvads.v14i5.7603

AUDI, S. G. Avaliação das condições higiênico sanitárias das feiras livres do município de São Paulo - SP. 2002, 94f. Dissertação (Mestrado em Saúde Pública) - Faculdade de Saúde Pública, Universidade de São Paulo, São Paulo, 2002.

Agência Nacional de Vigilância Sanitária. Resolução - ANVISA. RDC n. 12, de 02 de janeiro de 2001. Dispõe sobre os princípios gerais para o estabelecimento de critérios e padrões microbiológicos para alimentos. Disponível em:

$<$ http://www.anvisa.gov.br/ALIMENTOS/seguranca/capacita_rh.htm>. Acessado em: $20 \mathrm{de}$ abril de 2020.

BRASIL. Ministério da Agricultura Pecuária e Abastecimento. Decreto no 9.013, de 29 de março de 2017. Regulamenta a inspeção industrial e sanitária de produtos de origem animal, que disciplina a fiscalização e a inspeção industrial e sanitária de produtos de origem animal, Brasilia, DF, 2017.

BRASIL. Secretaria Nacional de Vigilância Sanitária. Divisão Nacional de Vigilância Sanitária de Alimentos. Portaria no 451. Diário Oficial da União. Brasília, 22 set. 1997.

CAMPOS, L.; TRABULSI, R. T.; ALERTHUM, F.; CANDEIAS, J. N.; GOMPETZ, O. F. Microbiologia, 3. ed, São Paulo: Ed. Atheneu, 1999, 586 p.

FRANCO, B. D. G. M.; LANDGRAF, M. Microbiologia dos alimentos. São Paulo: Atheneu, 2005. 182p. 
FRANCO, R. M.; MANTILLA, S. P. S.; GOUVÊA, R.; OLIVEIRA, L. A. T. Ocorrência de Escherichia coli em suínos abatidos nos Estados do Rio de Janeiro, Minas Gerais, Paraná e Santa Catarina utilizando diferentes metodologias de isolamento. Revista Portuguesa de Ciências Veterinárias, v. 103. p. 209-218. 2008.

GOMES, P. M. DE A.; BARBOSA, J. G.; COSTA, E. R. DA; SANTOS JUNIOR. I. G. DOS. Avaliações das condições higiênicas sanitárias das carnes comercializadas na feira livre do município de Catolé do Rocha-PB. Revista Verde de Agroecologia e Desenvolvimento Sustentável, v. 7, n. 1, p. 225-232, 2012.

JAY, J. M. Microbiologia de alimentos. 6. ed. Porto Alegre: Ed. Artmed, 2005.

KONEMAN, E. W.; ALLEN, S. D.; JANDA, W. M.; SCHRECKENBERGER, P. C.; JUNIOR, W. C. W. Diagnóstico Microbiológico. Texto e Atlas Colorido. 5.ed. Rio de Janeiro: Medsi, 2001, 1466p.

LIRA, G. M.; PEREIRA, W. G. Avaliação da qualidade de peixes comercializados na cidade de Maceió - AL. Revista Higiene Alimentar, v. 15, n. 84, p. 67-74, 2001.

LUNDGREN, P. U.; SILVA, J. A.; FERNANDES, T. M. Perfil da qualidade higiênico-sanitária carne bovina comercializada em feiras livres de mercados públicos de João Pessoa/PB- Brasil.

Alimentos e Nutrição, v. 20, n. 1, p. 113-119, 2009.

MARTINS, T. D. D.; MOREIRA, R. T.; SILVA, L. DA P. G. DA; BATISTA, E. DE S.; SANTOS, R. J. C. DOS; SANTOS, J. G. DOS; PEREIRA, W. E.; SILVA, R. R. D. A. Avaliação microbiológica da carne suína in natura, comercializada na microrregião do Brejo Paraibano.

Revista Higiene Alimentar, v. 21, p. 77-81, 2007.

MERK, E. Manual de meios de cultura. Alemanha, 1994. 364p.

MIELE, M.; MACHADO, J. S. Relatório técnico: Os caminhos da suinocultura. Disponível em: 〈www.abipecs.org.br〉. Acesso em: 28 março de 2020.

Ministério da Agricultura, Pecuária e Abastecimento. Instrução Normativa n o 76, de 30 de novembro de 2018. (2018). Diário Oficial da União. Brasília: MAPA. Disponível em: <http://www.in.gov.br/materia/-/asset_publisher/Kujrw0TZC2Mb/content/id/52750137/do1 2018-11-30-instrucao-normativa-n-76-de-26-de-novembro-de-2018-52749894IN\%2076>. Acessado em: 01 de outubro de 2020.

OLIVEIRA, R. B. A.; ROLIM, M. B. Q.; MOURA, A. P. B. L.; MOTA, R. A. Avaliação higiênico sanitária dos boxes que comercializam carnes em dois mercados públicos da cidade do Recife PE/Brasil. Revista Brasileira de Medicina Veterinária, v. 2, p. 10-16, 2008.

PORTO, E. Qualidade da carne: microbiologia de carnes. Varela São Paulo-SP 2006 p.101131.

SALES, L. E. M.; ABANTES, R. M.; OLIVEIRA, A. R. M.; SOARES, K. M. P.; MENDES, C. G.; LEITE, A. I.; SILVA, J. B. A. Qualidade microbiológica da carne suína comercializada em Mossoró- RN. Acta Veterinaria Brasilica, v. 7, n. 4, p. 306-310, 2013. https://doi.org/10.21708/avb.2013.7.4.3489 
SILVA FILHA, O. L. Experiências Brasileiras na criação de suínos locais. Revista Computadorizada de Producción Porcina, v. 15, n. 1, p. 41-50, 2008.

SILVA JUNIOR, E. A. Manual de controle higiênico-sanitário em serviços de alimentação. 6. ed, São Paulo: Varela, 2007.

SILVA, N.; JUNQUEIRA, V. C. A.; SILVEIRA, N. F. A. Manual de Métodos de Análise Microbiológica de Alimentos. 2. ed. São Paulo: Varela, 2001.

SIQUEIRA, R. S. Manual de Microbiologia de Alimentos. Centro Nacional de Pesquisa de Tecnologia Agroindustrial de Alimentos. Rio de Janeiro: EMBRAPA - CTAA, 1995, 159p.

SOUZA, M. C. Análise microbiológica da carne suína in natura comercializada em feiras livres da microrregião do Brejo Paraibano, Areia PB. 2012, 37f. Trabalho de Conclusão de Curso (Graduação em Zootecnia) - Universidade Federal da Paraíba, Areia, 2012.

SPECK, M. L. Compendium for the microbiological examination of foods. Washington, D. C. :American public health association. 1976, 701p.

THOMS, E.; ROSSA, L. S.; STAHLKE, E. V. R.; FERRO, I. D.; MACEDO, R. E. F. Perfil de consumo e percepção da qualidade da carne suína por estudantes de nível médio da cidade de Irati, PR. Revista Acadêmica: Ciências Agrárias e Ambientais, v. 8, n. 4, p. 449-459. 2010.

WELKER, C. A. D.; BOTH, J. M. C; LONGARAY, S. M.; HAAS, S.; SOEIRO, M. L. T.; RAMOS, R. C. Análise microbiológica dos alimentos envolvidos em surtos de doenças transmitidas por alimentos (DTA) ocorridos no estado do Rio Grande do Sul, Brasil. Revista Brasileira Biociências, v. 8, n. 1, p. 44-48, 2010. 